\title{
Complete genome sequence of Atopobium parvulum type strain (IPP 1246 ${ }^{\mathrm{T}}$ )
}

\author{
Alex Copeland ${ }^{1}$, Johannes Sikorski ${ }^{2}$, Alla Lapidus ${ }^{1}$, Matt Nolan ${ }^{1}$, Tijana Glavina Del Rio ${ }^{1}$, Su- \\ san Lucas ${ }^{1}$, Feng Chen ${ }^{1}$, Hope Tice ${ }^{1}$, Sam Pitluck ${ }^{1}$, Jan-Fang Cheng ${ }^{1}$, Rüdiger Pukall ${ }^{2}$, Olga \\ Chertkov $^{1,3}$, Thomas Brettin ${ }^{1,3}$, Cliff Han ${ }^{1,3}$, John C. Detter ${ }^{1,3}$, Cheryl Kuske ${ }^{1,3}$, David Bruce ${ }^{1,3}$, \\ Lynne Goodwin ${ }^{1,3}$, Natalia Ivanova ${ }^{1}$, Konstantinos Mavromatis ${ }^{1}$, Natalia Mikhailova ${ }^{1}$, Amy \\ Chen $^{4}$, Krishna Palaniappan ${ }^{4}$, Patrick Chain ${ }^{1,5}$, Manfred Rohde ${ }^{6}$, Markus Göker ${ }^{2}$, Jim Bris- \\ tow $^{1}$, Jonathan A. Eisen ${ }^{1,7}$, Victor Markowitz ${ }^{4}$, Philip Hugenholtz ${ }^{1}$, Nikos C. Kyrpides ${ }^{1}$, Hans- \\ Peter Klenk ${ }^{2 *}$, and John C. Detter ${ }^{1,3}$ \\ ${ }^{1}$ DOE Joint Genome Institute, Walnut Creek, California, USA \\ 2 DSMZ - German Collection of Microorganisms and Cell Cultures GmbH, Braunschweig, \\ Germany \\ ${ }^{3}$ Los Alamos National Laboratory, Bioscience Division, Los Alamos, New Mexico, USA \\ ${ }^{4}$ Biological Data Management and Technology Center, Lawrence Berkeley National Labora- \\ tory, Berkeley, California, USA \\ ${ }^{5}$ Lawrence Livermore National Laboratory, Livermore, California, USA \\ ${ }^{6} \mathrm{HZI}$ - Helmholtz Centre for Infection Research, Braunschweig, Germany \\ ${ }^{7}$ University of California Davis Genome Center, Davis, California, USA \\ *Corresponding author: Hans-Peter Klenk
}

\begin{abstract}
Keywords: halitosis, obligately anaerobic, human respiratory tract, risk group 2, malodor, Coriobacteriaceae

Atopobium parvulum (Weinberg et al. 1937) Collins and Wallbanks 1993 comb. nov. is the type strain of the species and belongs to the genomically yet unstudied Atopobium/Olsenella branch of the family Coriobacteriaceae. The species A. parvulum is of interest because its members are frequently isolated from the human oral cavity and are found to be associated with halitosis (oral malodor) but not with periodontitis. Here we describe the features of this organism, together with the complete genome sequence, and annotation. This is the first complete genome sequence of the genus Atopobium, and the 1,543,805 bp long single replicon genome with its 1369 protein-coding and 49 RNA genes is part of the Genomic Encyclopedia of Bacteria and Archaea project.
\end{abstract}

\section{Introduction}

Strain IPP $1246^{\mathrm{T}}$ (= DSM 20469 = ATCC $33793=$ JCM 10300) is the type strain of the species Atopobium parvulum and was first described by Weinberg et al. 1937 as 'Streptococcus parvulus' (basonym) [1]. In 1992 it was reclassified as A. parvulum [2]. A. parvulum is of high interest because it has frequently been isolated from the human oral cavity, especially from the tongue dorsum, where it has been associated with patients suffering from halitosis (oral malodor) [3,4]. In general, the malodorous compounds are volatile sulfur compounds, with the most frequent ones being hydrogen sulfide, methyl mercaptan, and dimethyl sulfide, which are produced by bacterial metabolism of the sulfur containing amino acids cysteine and methionine [3,4]. However, for A. parvulum itself, the production of these substances has not yet been studied. A. parvulum has not been found to be significantly associated with chronic periodontitis, though a participation in periodontitis can not be fully excluded [5]. Nevertheless, A. parvulum has been associated with odontogenic infections, e.g. dental implants, but also with the saliva of healthy subjects [6]. Here we present a summary classification and a set of features for A. parvulum IPP $1246^{\mathrm{T}}$ together with the description of the complete genomic sequencing and annotation. 
Copeland, et al.

\section{Classification and features}

Phylotypes with significant 16 S sequence similarity to strain IPP $1246^{\mathrm{T}}$ were observed from intubated patients (EF510777) and from metagenomic human skin surveys (GQ081350) [7]. No significant similarities were found in human gut metagenomes (highest similarity is 92\%, BABE01011651) [8], or in marine metagenomes (87\%, AACY020304192) [9] (status June 2009).
Figure 1 shows the phylogenetic neighborhood of $A$. parvulum strain IPP P1246 ${ }^{\mathrm{T}}$ in a $16 \mathrm{~S}$ rRNA based tree. The sequence of the sole copy of the $16 \mathrm{~S}$ rRNA gene in the genome is identical with the previously published sequence generated from ATCC 22793 (AF292372), but differs by four nucleotides from the sequence used for the last taxonomic emendation (X67150) [2].

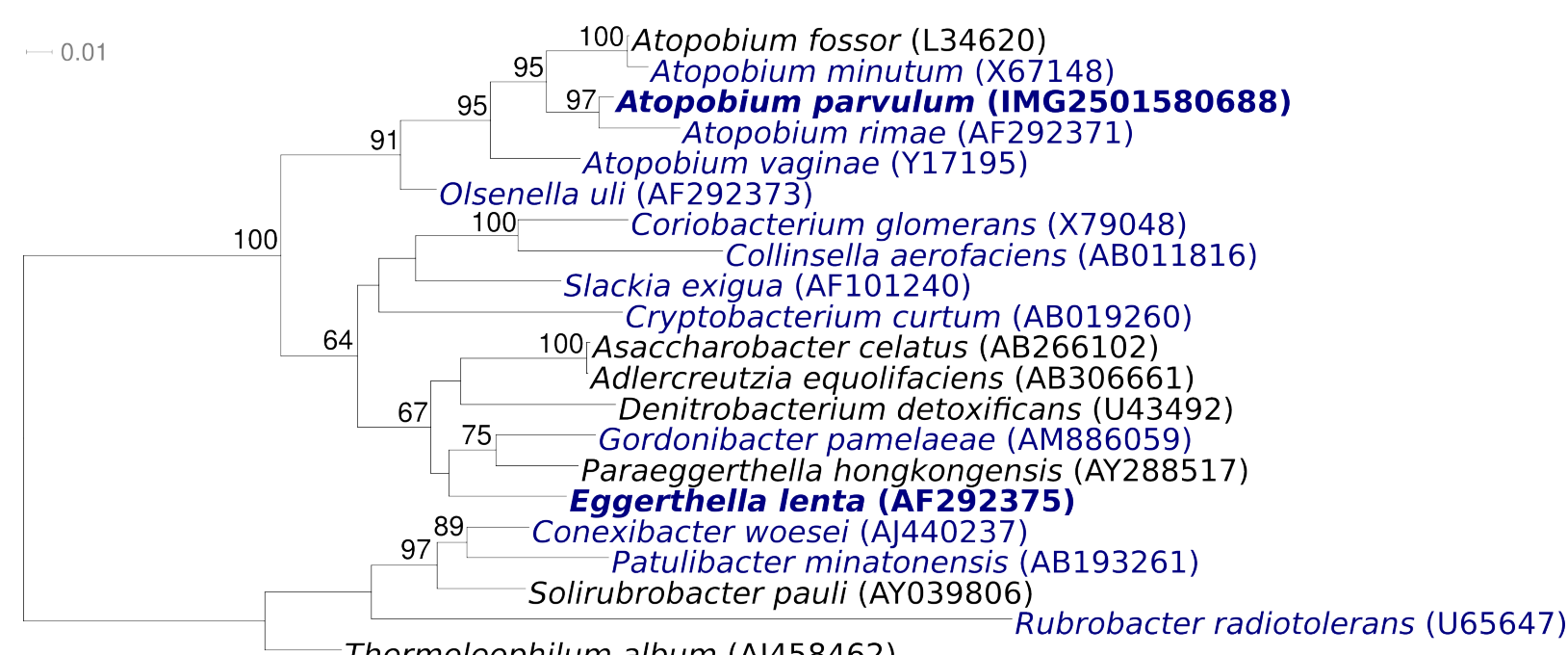

Thermoleophilum album (AJ458462)

Figure 1. Phylogenetic tree of A. parvulum strain IPP $1246^{\top}$, all other type strains of the genus Atopobium and the type strains of all other genera within the Coriobacteriaceae, inferred from 1345 aligned characters [10,11] of the 16S rRNA gene sequence under the maximum likelihood criterion [12]. The tree was rooted with the type strains of the genera within the subclass Rubrobacteridae. The branches are scaled in terms of the expected number of substitutions per site. Numbers above branches are support values from 1000 bootstrap replicates if larger than 60\%. Lineages with type strain genome sequencing projects registered in GOLD [13] are shown in blue, published genomes in bold, including two of which are reported in this issue of SIGS [14,15]

The cells are cocci (approximately 0.3 to $0.6 \mu \mathrm{m}$ in diameter) that occur singly, in pairs, in clumps, and in short chains, occasionally with central swelling [16,17] (Table 1 and Figure 2). The strains are non-motile and obligate anaerobic. Interestingly, growth is substantially stimulated by $0.02 \%$ (vol/vol) Tween 80 and by $10 \%$ (vol/vol) rabbit serum added to culture media [16]. Strain IPP $1246^{\mathrm{T}}$ is susceptible to chloramphenicol (12 $\mu \mathrm{g} / \mathrm{ml})$, clindamycin $(1.6 \mu \mathrm{g} / \mathrm{ml})$, erythromycin (3 $\mu \mathrm{g} / \mathrm{ml})$, penicillin $\mathrm{G}(2 \mathrm{U} / \mathrm{ml})$, and tetracycline $(6$ $\mu \mathrm{g} / \mathrm{ml}$ ) [17].

Strain IPP $1126^{\mathrm{T}}$ produces acid (final $\mathrm{pH}<4.7$ ) from cellobiose, esculin, fructose, galactose, glucose, inulin, lactose, maltose, mannose, salicin, sucrose, and trehalose; erythritol and xylose were weakly fermented; no acid was produced from amygdalin, arabinose, glycerol, glycogen, inositol, mannitol, melezitose, melibiose, pectin, raffinose, rhamnose, ribose, sorbitol, or starch. Esculin was hydrolyzed; neither starch nor hippurate was hydrolyzed. Nitrate was not reduced. Indole was not formed. A solid acid curd formed in milk; neither milk, gelatin, nor meat was digested. Neither catalase, urease, deoxyribonuclease, lecithinase, nor lipase was detected [17]. Other enzyme activities are positive for acid phosphatase, alanine arylamidase, arginine arylamidase, $\beta$-galactosidase, leucine arylamidase, pyroglutamic acid arylamidase, glycine arylamidase, tyrosine arylamidase, 
but negative for arginine dihydrolase, histidine arylamidase, proline arylamidase, serine arylamidase, as determined using the API system [24].

\section{Chemotaxonomy}

The chemotaxonomy of $A$. parvulum IPP $1246^{\mathrm{T}}$ is unfortunately hardly studied. There are no data known on the polar lipids. The strain possesses cell-wall peptidoglycan of type A $4 \alpha$, L-Lys-D-Asp (type A11.31 according to the DSMZ catalogue of strains) [25]. The major cellular fatty acids (FAME: fatty acid methyl ester; DMA: dimethylacetyl) are $\mathrm{C}_{18: 1}$ cis-9 (38.2\%, FAME), $\mathrm{C}_{18: 1}$ cis- 9 (24.1\%, DMA), $\mathrm{C}_{16: 1}$ cis-9 (5.0\%, FAME), $\mathrm{C}_{17: 1}$ cis-8 (5.0\%, FAME), $\mathrm{C}_{18: 1} \mathrm{c} 11 / \mathrm{t} 9 / \mathrm{t} 6$ (5.0\%, FAME), $\mathrm{C}_{18: 1}$ cis-11 (3.9\%, DMA), $\mathrm{C}_{14: 0}\left(3.4 \%\right.$, FAME), $\mathrm{C}_{10: 0}(3.0 \%$, FAME) [16].

Table 1. Classification and general features of A. parvulum IPP $1146^{\top}$ according to the MIGS recommendations [18].

\begin{tabular}{|c|c|c|c|}
\hline MIGS ID & Property & Term & $\begin{array}{c}\text { Evidence } \\
\text { code }\end{array}$ \\
\hline & \multirow{10}{*}{ Current classification } & Domain Bacteria & TAS [19] \\
\hline & & Phylum Actinobacteria & TAS [20] \\
\hline & & Class Actinobacteria & TAS $[20]$ \\
\hline & & Subclass Coriobacteridae & TAS $[21]$ \\
\hline & & Order Coriobacteriales & TAS $[21]$ \\
\hline & & Suborder "Coriobacterineae" & TAS $[21]$ \\
\hline & & Family Coriobacteriaceae & TAS $[21]$ \\
\hline & & Genus Atopobium & TAS [2] \\
\hline & & Species Atopobium parvulum & TAS [2] \\
\hline & & Type strain IPP 1246 & \\
\hline & Gram stain & positive & TAS [16] \\
\hline & Cell shape & small cocci that occasionally appear to be elliptical & TAS [16] \\
\hline & Motility & nonmotile & TAS [17] \\
\hline & Sporulation & nonsporulating & TAS [16] \\
\hline & Temperature range & $25^{\circ} \mathrm{C}-45^{\circ} \mathrm{C}$ & TAS [17] \\
\hline & Optimum temperature & $37^{\circ} \mathrm{C}-45^{\circ} \mathrm{C}$ & TAS [17] \\
\hline & Salinity & less than $6.5 \% \mathrm{NaCl}$ & TAS [17] \\
\hline \multirow[t]{3}{*}{ MIGS-22 } & Oxygen requirement & obligate anaerobic & TAS [17] \\
\hline & Carbon source & $\begin{array}{l}\text { acid production from cellobiose, esculin, fructose, } \\
\text { galactose, glucose, inulin, lactose, maltose, man- } \\
\text { nose, salicin, sucrose, and trehalose }\end{array}$ & TAS $[17]$ \\
\hline & Energy source & carbohydrates & TAS [17] \\
\hline MIGS-6 & Habitat & human respiratory tract. & TAS $[1,17]$ \\
\hline MIGS-15 & Biotic relationship & free living & NAS \\
\hline \multirow[t]{3}{*}{ MIGS-14 } & Pathogenicity & associated with halitosis and human oral infections & TAS $[3,4,6]$ \\
\hline & Biosafety level & 2 & TAS [22] \\
\hline & Isolation & $\begin{array}{l}\text { unknown for this specific strain, but Weinberg et al } \\
\text { reported that the principal habitat was the respirato- } \\
\text { ry tract. }\end{array}$ & TAS $[1,17]$ \\
\hline MIGS-4 & Geographic location & unknown, probably France & TAS $[1,17]$ \\
\hline MIGS-5 & Sample collection time & before 1937 & TAS $[1,17]$ \\
\hline $\begin{array}{l}\text { MIGS-4.1 } \\
\text { MIGS-4.2 }\end{array}$ & Latitude - Longitude & unknown & \\
\hline MIGS-4.3 & Depth & not reported & \\
\hline MIGS-4.4 & Altitude & not reported & \\
\hline
\end{tabular}

Evidence codes - IDA: Inferred from Direct Assay (first time in publication); TAS: Traceable Author Statement (i.e., a direct report exists in the literature); NAS: Non-traceable Author Statement (i.e., not directly observed for the living, isolated sample, but based on a generally accepted property for the species, or anecdotal evidence). These evidence codes are from the Gene Ontology project [23]. If the evidence code is IDA the property was directly observed for a living isolate by one of the authors or another expert mentioned in the acknowledgements. 


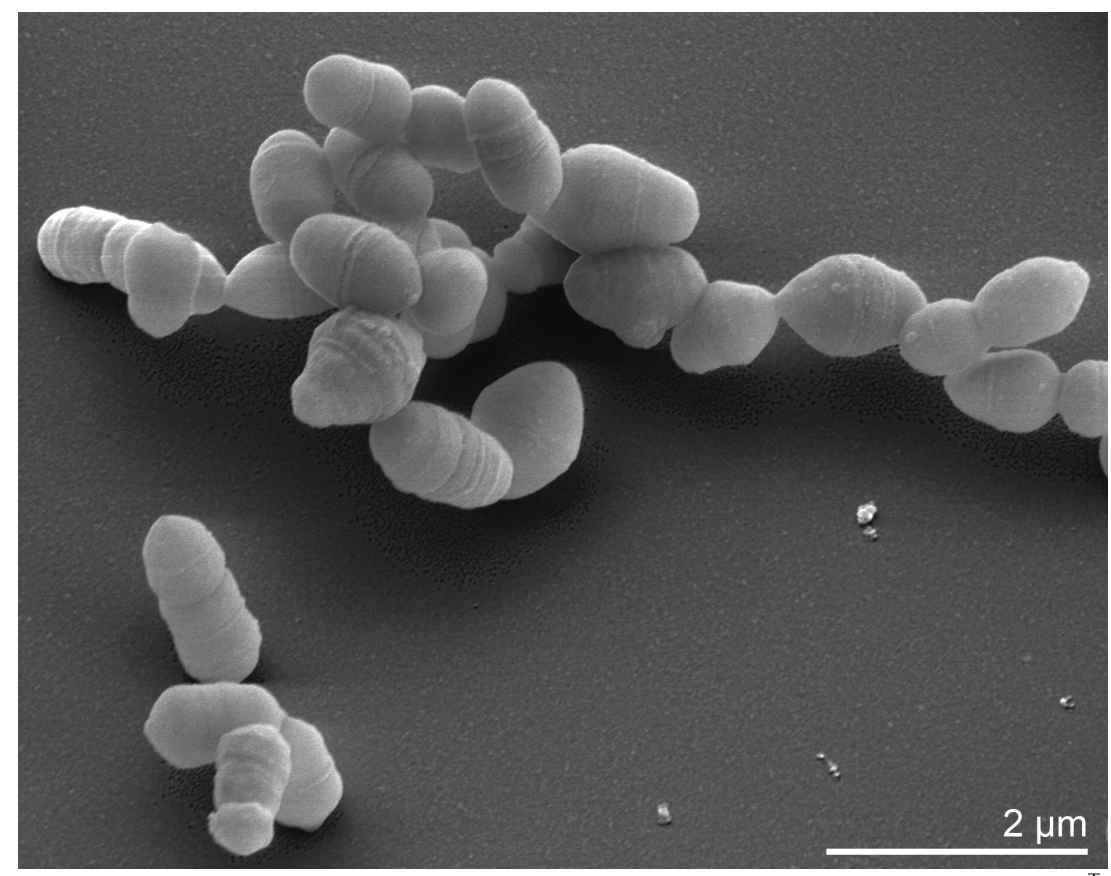

Figure 2. Scanning electron micrograph of $A$. parvulum IPP $1246^{\top}$

\section{Genome sequencing and annotation}

\section{Genome project history}

This organism was selected for sequencing on the basis of each phylogenetic position, and is part of the Genomic Encyclopedia of Bacteria and Archaea project. The genome project is deposited in the Genome OnLine Database [13] and the complete genome sequence is deposited in GenBank Sequencing, finishing and annotation were performed by the DOE Joint Genome Institute (JGI). A summary of the project information is shown in Table 2.

\section{Growth conditions and DNA isolation}

A. parvulum strain IPP 1246, DSM 20469, was grown anaerobically in DSMZ medium 104 (modified PYG; Medium [26]) at $37^{\circ} \mathrm{C}$. DNA was isolated from $0.5-1 \mathrm{~g}$ of cell paste using the JGI CTAP procedure with a modified protocol for cell lysis as described in Wu et al. [27].

Table 2. Genome sequencing project information

\begin{tabular}{|c|c|c|}
\hline MIGS ID & Property & Term \\
\hline MIGS-31 & Finishing quality & Finished \\
\hline MIGS-28 & Libraries used & $\begin{array}{l}\text { Two Sanger libraries: } 8 \mathrm{~kb} \text { pMCL200 } \\
\text { and fosmid pcc1 Fos One } 454 \text { pyro- } \\
\text { sequence standard library }\end{array}$ \\
\hline MIGS-29 & Sequencing platforms & ABI3730, 454 GS FLX \\
\hline MIGS-31.2 & Sequencing coverage & 7.8× Sanger; $43.4 \times$ pyrosequence \\
\hline MIGS-30 & Assemblers & Newbler, phrap \\
\hline \multirow[t]{6}{*}{ MIGS-32 } & Gene calling method & Prodigal, GenePRIMP \\
\hline & Genbank ID & СР001721 \\
\hline & Genbank Date of Release & September 9, 2009 \\
\hline & GOLD ID & Gc01099 \\
\hline & NCBI project ID & 29401 \\
\hline & Database: IMG-GEBA & 2501533209 \\
\hline \multirow[t]{2}{*}{ MIGS-13 } & Source material identifier & DSM 20469 \\
\hline & Project relevance & Tree of Life, GEBA \\
\hline
\end{tabular}




\section{Genome sequencing and assembly}

The genome was sequenced using a combination of Sanger and 454 sequencing platforms. All general aspects of library construction and sequencing performed at the JGI can be found on the JGI website. 454 Pyrosequencing reads were assembled using the Newbler assembler version 1.1.02.15 (Roche). Large Newbler contigs were broken into 1,716 overlapping fragments of $1000 \mathrm{bp}$ and entered into assembly as pseudoreads. The sequences were assigned quality scores based on Newbler consensus q-scores with modifications to account for overlap redundancy and to adjust inflated q-scores. A hybrid 454/Sanger assembly was made using the parallel phrap assembler (High Performance Software, LLC). Possible mis-assemblies were corrected with Dupfinisher [28] or transposon bombing of bridging clones (Epicentre Biotechnologies, Madison, WI). Gaps between contigs were closed by editing in Consed, custom primer walk or PCR amplification. A total of 125 Sanger finishing reads were produced to close gaps, to resolve repetitive regions, and to raise the quality of the finished sequence. The error rate of the completed genome sequence is less than 1 in 100,000 . Together all sequence types provided $51.2 \mathrm{x}$ coverage of the genome. The final assembly contains 12,842 Sanger and 359,479 pyrosequence reads.

\section{Genome annotation}

Genes were identified using Prodigal [29] as part of the Oak Ridge National Laboratory genome annotation pipeline, followed by a round of manual curation using the JGI GenePRIMP pipeline [30]. The predicted CDSs were translated and used to search the National Center for Biotechnology Information (NCBI) nonredundant database, UniProt, TIGRFam, Pfam, PRIAM, KEGG, COG, and InterPro databases. Additional gene prediction analysis and functional annotation were performed within the Integrated Microbial Genomes Expert Review (IMG-ER) platform [31].

\section{Genome properties}

The genome is 1,543,805 bp long and comprises one main circular chromosome with a $45.7 \%$ GC content (Table 3 and Figure 3). Of the 1419 genes predicted, 1369 were protein coding genes, and 50 RNAs. Sixteen pseudogenes were also identified. The majority of the genes (74.5\%) were assigned with a putative function while the remaining ones were annotated as hypothetical proteins. The distribution of genes into COGs functional categories is presented in Table 4.

Table 3. Genome Statistics

\begin{tabular}{lrr}
\hline Attribute & Value & \% of Total \\
\hline Genome size (bp) & $1,543,805$ & $100.00 \%$ \\
DNA Coding region (bp) & $1,396,223$ & $90.44 \%$ \\
DNA G+C content (bp) & 705,312 & $45.69 \%$ \\
Number of replicons & 1 & \\
Extrachromosomal elements & 0 & \\
Total genes & 1419 & $100.00 \%$ \\
RNA genes & 49 & $3.52 \%$ \\
rRNA operons & 1 & \\
Protein-coding genes & 1369 & $96.48 \%$ \\
Pseudo genes & 16 & $1.13 \%$ \\
Genes with function prediction & 1059 & $74.63 \%$ \\
Genes in paralog clusters & 69 & $4.86 \%$ \\
Genes assigned to COGs & 1096 & $77.24 \%$ \\
Genes assigned Pfam domains & 1084 & $76.39 \%$ \\
Genes with signal peptides & 240 & $16.91 \%$ \\
Genes with transmembrane helices & 339 & $23.89 \%$ \\
CRISPR repeats & 0 & \\
\hline
\end{tabular}




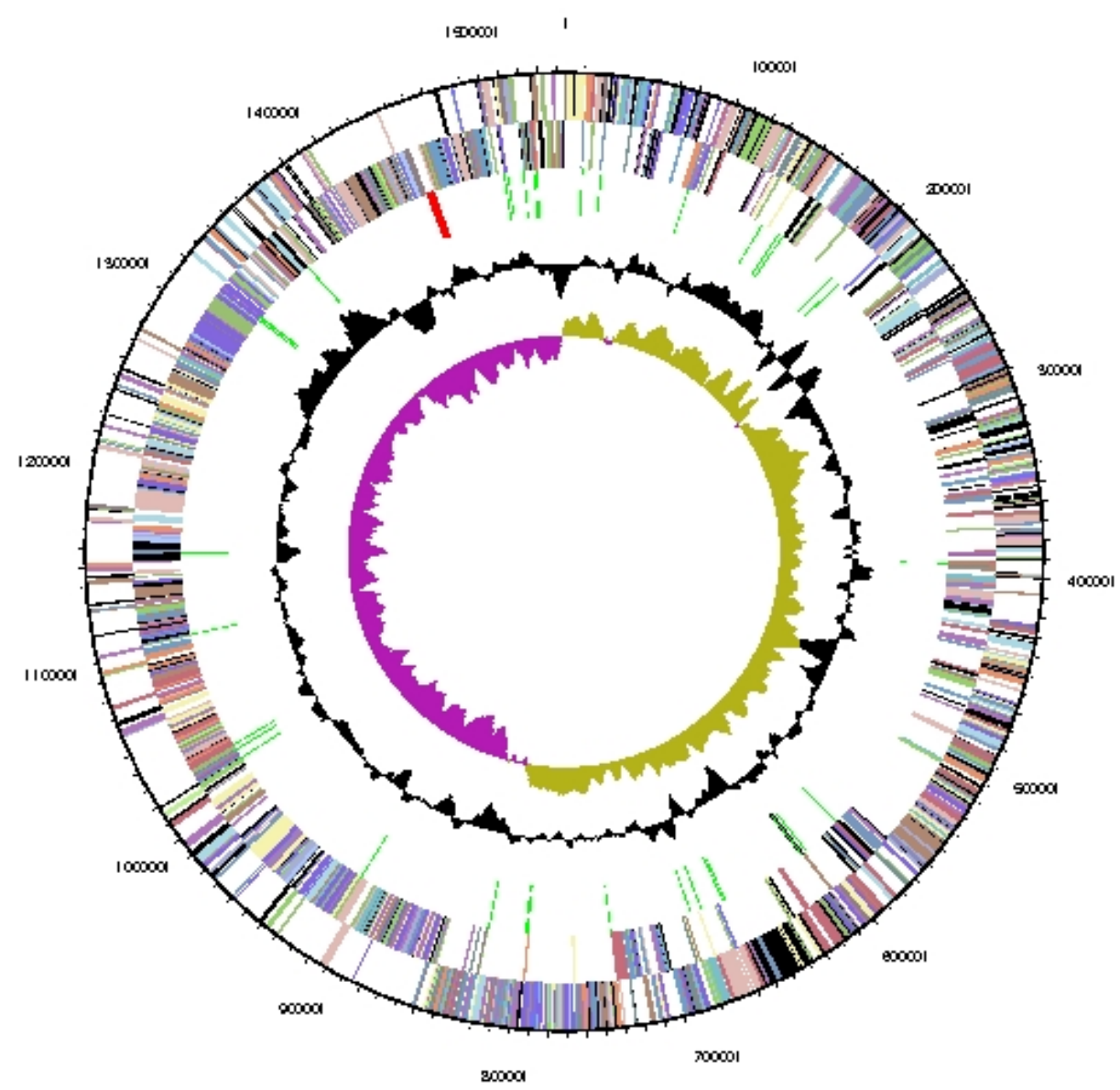

Figure 3. Graphical circular map of the genome. From outside to the center: Genes on forward strand (color by COG categories), Genes on reverse strand (color by COG categories), RNA genes (tRNAs green, rRNAs red, other RNAs black), GC content, GC skew.

Table 4. Number of genes associated with the general COG functional categories

\begin{tabular}{lrrl}
\hline Code & Value & \% age & Description \\
\hline J & 128 & 9.3 & Translation, ribosomal structure and biogenesis \\
A & 0 & 0.0 & RNA processing and modification \\
K & 85 & 6.2 & Transcription \\
L & 72 & 5.3 & Replication, recombination and repair \\
$\mathrm{B}$ & 1 & 0.1 & Chromatin structure and dynamics \\
D & 18 & 1.3 & Cell cycle control, mitosis and meiosis \\
Y & 0 & 0.0 & Nuclear structure \\
V & 42 & 3.1 & Defense mechanisms \\
T & 46 & 3.4 & Signal transduction mechanisms \\
M & 70 & 5.1 & Cell wall/membrane biogenesis \\
N & 1 & 0.1 & Cell motility \\
Z & 0 & 0.0 & Cytoskeleton \\
W & 0 & 0.0 & Extracellular structures \\
U & 20 & 1.5 & Intracellular trafficking and secretion \\
O & 44 & 3.2 & Posttranslational modification, protein turnover, chaperones \\
C & 44 & 3.2 & Energy production and conversion \\
G & 115 & 8.4 & Carbohydrate transport and metabolism \\
\hline
\end{tabular}


Table 4. Number of genes associated with the general COG functional categories (cont.)

\begin{tabular}{lrrl}
\hline Code & Value & \% age & Description \\
\hline $\mathrm{E}$ & 105 & 7.7 & Amino acid transport and metabolism \\
$\mathrm{F}$ & 53 & 3.9 & Nucleotide transport and metabolism \\
$\mathrm{H}$ & 37 & 2.7 & Coenzyme transport and metabolism \\
$\mathrm{I}$ & 23 & 1.7 & Lipid transport and metabolism \\
$\mathrm{P}$ & 59 & 4.3 & Inorganic ion transport and metabolism \\
$\mathrm{Q}$ & 11 & 0.8 & Secondary metabolites biosynthesis, transport and catabolism \\
$\mathrm{R}$ & 125 & 9.1 & General function prediction only \\
$\mathrm{S}$ & 90 & 6.6 & Function unknown \\
- & 273 & 19.9 & Not in COGs \\
\hline
\end{tabular}

\section{Acknowledgements}

We would like to gratefully acknowledge the help of Katja Steenblock for growing A. parvulum cultures and Susanne Schneider for DNA extraction and quality analysis (both at DSMZ). This work was performed under the auspices of the US Department of Energy Office of Science, Biological and Environmental Research Program, and by the University of California,

\section{References}

1. Weinberg M, Nativelle R, Prévot AR. Les microbes anaeobies. Masson and Co., Paris. 1937.

2. Collins MD, Wallbanks S. Comparative sequence analyses of the 16S rRNA genes of Lactobacillus minutus, Lactobacillus rimae and Streptococcus parvulus: proposal for the creation of a new genus Atopobium. FEMS Microbiol Lett 1992; 74: 235240. PubMed doi:10.1111/j.15746968.1992.tb05372.x

3. Kazor CE, Mitchell PM, Lee AM, Stokes LN, Loesche WJ, Dewhirst FE, Paster BJ. Diversity of bacterial populations on the tongue dorsa of patients with halitosis and healthy patients. J Clin Microbiol 2003; 41:558-563.

4. Riggio MP, Lennon A, Rolph HJ, Hodge PJ, Donaldson A, Maxwell AJ, Bargg J. Molecular identification of bacteria on the tongue dorsum of subjects with and without halitosis. Oral Dis 2008; 14: 251-258. PubMed doi:10.1111/j.1601$\underline{0825.2007 .01371 . x}$

5. Kumar PS, Griffen AL, Barton JA, Paster BJ, Moeschberger ML, Leys EJ. New bacterial species associated with chronic periodontitis. J Dent Res 2003; 82: 338-344. PubMed doi:10.1177/154405910308200503

6. Downes J, Munson MA, Spratt DA, Konen E, Tarkka E, Jousimies-Somer H, Wade WG. Characterisation of Eubacterium-like strains isolated from
Lawrence Berkeley National Laboratory under contract No. DE-AC02-05CH11231, Lawrence Livermore National Laboratory under Contract No. DE-AC5207NA27344, and Los Alamos National Laboratory under contract No. DE-AC02-06NA25396, as well as German Research Foundation (DFG) INST 599/1-1.

oral infections. J Med Microbiol 2001; 50: 947951. PubMed

7. Grice EA, Kong HH, Conlan S, Deming CB, Davis J, Young AC, NISC Comparative Sequencing Program, Bouffard GG, Blakesley RW, Murray RR, et al. Topographical and temporal diversity of the human skin microbiome. Science 2009; 324: 1190-1192. PubMed

8. Kurokawa K, Itoh T, Kuwahara T, Oshima K, Toh H, Toyoda A, Takami H, Morita H, Sharma VK, Srivastava TP, et al. Comparative metagenomics revealed commonly enriched gene sets in human gut microbiomes. DNA Res 2007; 14: 169-181. PubMed doi:10.1093/dnares/dsm018

9. Venter JC, Remington K, Heidelberg JF, Halpern AL, Rusch D, Eisen JA, Wu D, Paulsen J, Nelson $\mathrm{KE}$, Nelson W, et al. Environmental genome shotgun sequencing of the Sargasso Sea. Science 2004; 304: 66-74. PubMed doi:10.1126/science.1093857

10. Castresana J. Selection of conserved blocks from multiple alignments for their use in phylogenetic analysis. Mol Biol Evol 2000; 17: 540-552. PubMed

11. Lee C, Grasso C, Sharlow MF. Multiple sequence alignment using partial order graphs. BioinformatiCs 2002; 18: 452-464.

PubMed doi:10.1093/bioinformatics/18.3.452 
Copeland, et al.

12. Stamatakis A, Hoover P, Rougemont J. A Rapid Bootstrap Algorithm for the RAxML Web Servers. Syst Biol 2008; 57: 758-771. PubMed doi:10.1080/10635150802429642

13. Liolios K, Mavromatis K, Tavernarakis N, Kyrpides NC. The Genomes On Line Database (GOLD) in 2007: status of genomic and metagenomic projects and their associated metadata. Nucleic Acids Res 2008; 36: D475-D479.

PubMed doi:10.1093/nar/gkm884

14. Mavrommatis K, Pukall R, Rohde C, Chen F, Sims D, Brettin T, Kuske C, Detter JC, Han C, Lapidus A, et al. Complete genome sequence of Cryptobacterium curtum type strain (12-3T). Stand Genomic Sci 2009; 1: 93-101. doi:10.4056/sigs.15195-

15. Saunders E, Pukall R, Abt B, Lapidus A, Galvina Del Rio T, Copeland A, Tice H, Cheng JF, Lucas S, Chen $\mathrm{F}$, et al. Complete genome sequence of $\mathrm{Eg}$ gerthella lenta type strain (IPP VPI 0255T). Stand Genomic Sci 2009; 1: 174-

182. doi:10.4056/sigs.33592

16. Olsen I, Johnson JL, Moore LVM, Moore WEC. Lactobacillus uli sp. nov. and Lactobacillus rimae sp. nov. from the human gingival crevice and emended descriptions of Lactobacillus minutus and Streptococcus parvulus. Int I Syst Bacteriol 1991; 41: 261-266. $\underline{\text { PubMed }}$

17. Cato EP. Transfer of Peptostreptococcus parvulus (Weinberg, Nativelle, and Prévot 1937) Smith 1957 to the Genus Streptococcus: Streptococcus parvulus (Weinberg, Nativelle, and Prévot 1937) comb, nov., nom. rev., emend. Int / Syst Bacteriol 1983; 33: 82-84.

18. Field D, Garrity G, Gray T, Morrison N, Selengut J, Sterk P, Tatusova T, Thomson N, Allen MJ, Angiuoli SV, et al. The minimum information about a genome sequence (MIGS) specification. Nat Biotechnol 2008; 26: 541-547.

PubMed doi:10.1038/nbt1360

19. Woese CR, Kandler O, Wheelis ML. Towards a natural system of organisms: proposal for the domains Archaea, Bacteria, and Eucarya. Proc Natl Acad Sci USA 1990; 87: 4576-4579. PubMed doi:10.1073/pnas.87.12.4576

20. Garrity GM, Holt J. In: Garrity GM, Boone DR, Castenholz RW, eds. Taxonomic Outline of the Archaea and Bacteria. Bergey's Manual of Systematic Bacteriology, 2nd Ed. Vol 1 The Archaea,
Deeply Branching and Phototrophic Bacteria. 2001 pp. 155-166

21. Stackebrandt E, Rainey FA, Ward-Rainey NL. Proposal for a New Hierarchic Classification System, Actinobacteria classis nov. Int / Syst Bacteriol 1997; 47: 479-491.

22. Anonymous. Biological Agents. Technical rules for biological agents www.baua.de TRBA 466.

23. Ashburner M, Ball CA, Blake JA, Botstein D, Butler H, Cherry JM, Davis AP, Dolinski K, Dwight SS, Eppig JT, et al. Gene ontology: tool for the unification of biology. The Gene Ontology Consortium. Nat Genet 2000; 25: 25-29. PubMed doi:10.1038/75556

24. Rodriguez Jovita MR, Collins MD, Sjoden B, Falsen E. Characterization of a novel Atopobium isolate from the human vagina: description of Atopobium vaginae sp. nov. Int / Syst Bacteriol 1999; 49: 1573-1576. PubMed

25. Weiss N. Cell wall structure of anaerobic cocci. Rev Inst Pasteur Lyon 1981; 14: 53-59.

26. List of media used at DSMZ for cell growth: http://www.dsmz.de/microorganisms/media_list.p $\mathrm{hp}$

27. Wu M, Hugenholtz P, Mavromatis K, Pukall R, Dalin E, Ivanova N, Kunin V, Goodwin L, Wu M, Tindall BJ, et al.. A phylogeny-driven genomic encyclopedia of Bacteria and Archaea. Nature 2009; (In press\}

28. Sims D, Brettin T, Detter JC, Han C, Lapidus A, Copeland A, Glavina Del Rio T, Nolan M, Chen F, Lucas $\mathrm{S}$, et al. Complete genome of Kytococcus sedentarius type strain $\left(541^{\mathrm{T}}\right)$. Stand Genomic Sci 2009; 1: 12-20. doi:10.4056/sigs.761

29. Anonymous. Prodigal Prokaryotic Dynamic Programming Genefinding Algorithm. Oak Ridge National Laboratory and University of Tennessee 2009 http://compbio.ornl.gov/prodigal

30. Pati A, Ivanova N, Mikhailova N, Ovchinikova G, Hooper SD, Lykidis A, Kyrpides NC. GenePRIMP: A Gene Prediction Improvement Pipeline for microbial genomes. (Submitted) 2009.

31. Markowitz VM, Mavromatis K, Ivanova NN, Chen IMA, Chu K, Kyrpides NC. Expert Review of Functional Annotations for Microbial Genomes. Bioinformatics 2009; 25: 2271-2278. PubMed doi:10.1093/bioinformatics/btp393 